\title{
Efficiency Evaluation of Extraction Methods for Analysis of OCPs and PCBs in Soils of Varying TOC
}

\author{
Ulrike Mülow-Stollin, Petra Lehnik-Habrink, Stephanie Kluge, Wolfram Bremser, \\ Christian Piechotta
}

Bundesanstalt für Materialforschung Und-Prüfung (BAM), Berlin, Germany

Email: ulrike.muelow@bam.de

How to cite this paper: Mülow-Stollin, U., Lehnik-Habrink, P., Kluge, S., Bremser, W. and Piechotta, C. (2017) Efficiency Evaluation of Extraction Methods for Analysis of OCPs and PCBs in Soils of Varying TOC. Journal of Environmental Protection, 8, 693713. https://doi.org/10.4236/jep.2017.86045

Received: May 11, 2017

Accepted: June 24, 2017

Published: June 27, 2017

Copyright (c) 2017 by authors and Scientific Research Publishing Inc. This work is licensed under the Creative Commons Attribution International License (CC BY 4.0).

http://creativecommons.org/licenses/by/4.0/

(c) (i) Open Access

\begin{abstract}
Organochlorine pesticides and polychlorinated biphenyls are toxic, carcinogenic, and have a high potential for bioaccumulation. Due to their stability, they are still considered an environmental problem even though the use of most of them has been phased out several decades ago. Soil is a matrix which can retain these contaminants to a great extent. This ability is often associated with the total organic carbon content (TOC). In order to judge the pollution status of soil and to make monitoring data more easily comparable a simple, yet robust extraction method is needed. Agitation solid-liquid-extraction is well suited for this purpose. However, the influence of TOC on the analyte recovery has to be known. For the presented study, 12 organochlorine pesticides and 7 polychlorinated biphenyls were spiked into four model soils with organic carbon contents between $1.6 \%-13.3 \%$. The matrices were extracted using solid-liquid extraction between 45 minutes and 16 hours. For comparison, all soils were also extracted using pressurised liquid extraction and Soxhlet extraction. After clean-up the extracts were measured using a gas chromatography-mass spectrometry (GC-MS) system. Statistical analysis of the results implied that the TOC content of the soils did not have significant influence on the extraction efficiency. A longer solid-liquid extraction time did not necessarily increase analyte recovery: Extraction for one hour resulted in 88\% recovery while 16 hour extraction led to $89 \%$. Thus, the efficiency of all the methods was comparable for all model soils. Additional investigations regarding GC liner performance highlighted the need for isotopically labelled standards during the analysis of thermolabile pesticides.
\end{abstract}

\section{Keywords}

POP, Soil Organic Matter, Solid-Liquid Extraction, Pressurised Liquid Extraction 


\section{Introduction}

Persistent organic pollutants (POPs) are a group of chemicals which all share a resistance towards degradation by hydrolysis or photolysis, as well as a potential for long-range transport and bioaccumulation. Additionally, all of them pose a threat towards human health as they are toxic, carcinogenic, or act as endocrine disruptors [1]. These features render these substances chemicals of long-term global concern. As they fulfill all of the criteria mentioned [2] [3] [4], the United Nations Environment Programme (UNEP) strives to fully eliminate several organochlorine pesticides (OCPs) and the polychlorinated biphenyls (PCBs), restrict their use, or terminate their unintentional production. The compounds concerned are listed in the Annexes of the Stockholm Convention which entered into force in 2004. In order to confirm whether measures which are taken to lower the global pollutant concentration are effective a global monitoring plan (GMP) was implemented by the UNEP in 2007 [5]. Since soil has a high potential to retain non-polar organic xenobiotics like OCPs and PCBs it is one of the matrices monitored under the GMP. Because of the diverse functional groups present in humic substances, contaminants are bound to soil organics by various mechanisms [6] [7]. The fraction of pollutant bound to organic matter which cannot be extracted using a certain technique is referred to as the non-extractable residue (NER) [8]. There has been some discussion as to whether NER are of actual im-portance for monitoring, since bound contaminants are not readily bioavailable and mobile [9]. However, it has been shown that xenobiotics may be re-released from NER [10] [11] [12]. This implies that for an assessment of the pollution status of a certain soil a possible future liberation of contaminants also needs to be taken into account. Hence, an exhaustive extraction is preferred for pollutant monitoring. It has been suggested that the potential for formation of NER is governed by the total organic carbon (TOC) content of soils [13]. If this is the case, it might be helpful to use different extraction methods or to review analyte concentrations depending on the TOC content of the soil in question. Today, the most commonly used soil extraction techniques for subsequent analysis of OCPs and PCBs are pressurised liquid extraction (PLE), Soxhlet extraction, and agitation solid-liquid-extraction (SLE). The laboratories assigned to the GMP are free in their choice of method [5]. As SLE does not require costly and sophisticated equipment, it is often used in commercial laboratories. The dependence of its extraction efficiency on soil TOC content has however not been studied in detail. Additionally, there are no studies available which compare the extraction efficiency of SLE with more intense methods under the influence of varying TOC contents. However, an understanding of the comparability of extraction methods is required for the interpretation and comparison of monitoring data. Due to the complexity of the analytical procedure (extraction, clean up, measurement) and the specific nature of the analytes the determination of OCPs and PCBs is related with measurement uncertainties of $20 \%-50 \%$ [14]. This makes a meaningful comparison exceedingly difficult. To overcome this problem the use of model soils for comparative studies is advisable as they offer sev- 
eral advantages over naturally contaminated soil. First of all, when only two characterised raw materials for production of several model soils are used the number of degrees of freedom is greatly reduced. Additionally, a well characterised, commercially available reference soil can be used. Naturally contaminated soils which adhere to certain criteria are not easily obtained. The most dominant influencing factor which remains is the total organic carbon (TOC) content of the model soils. Besides, this has the additional benefit that the nature of the humic fraction stays the same for all model soils. Finally, when uncontaminated model soils are spiked, the spiked concentration is known and can be the base of all analyte recovery calculations. This way the absolute percentage of extracted analyte can be evaluated. If instead a reference method was used to determine what $100 \%$ recovery signifies, the study design would be more prone to overlook actual over- and underestimations.

The project presented in this paper aimed to compare the performance of SLE of varying duration to that of PLE and Soxhlet extraction in soils of differing TOC contents. Model soils prepared from a reference soil and a compost were spiked with 12 OCPs and 7 PCBs which were selected as representatives for the whole group of contaminants. The aspects taken into ac-count for the choice of analytes were their ongoing use or production [15] [16], their presence in European soils [17], and the existence of well-established detection methods using gas chromatography [18].

\section{Materials and Methods}

\subsection{Chemicals and Reagents}

All solutions were prepared gravimetrically. For 12-point-calibration, appropriate volumes of Pesticide-Mix $17\left(10 \mu \mathrm{g} \cdot \mathrm{ml}^{-1}\right.$ in cyclohexane) and PCB Mix 3 (100 $\mu \mathrm{g} \cdot \mathrm{ml}^{-1}$ in isooctane) were diluted using cyclohexane. As internal standard a mixture of PCB 30 and PCB 209 (25.43 $\mu \mathrm{g} \cdot \mathrm{g}^{-1}$ and $25.23 \mu \mathrm{g} \cdot \mathrm{g}^{-1}$ in cyclohexane) and as injection standard a solution of PCB 198 (1.98 $\mu \mathrm{g} \cdot \mathrm{g}^{-1}$ in cyclohexane) were used. For extraction, acetone and cyclohexane (picograde) were employed. All of the above were purchased from LGC Standards GmbH (Wesel, Germany). For testing the influence of the GC liner a mixture of ${ }^{13} \mathrm{C}-4,4^{\prime} \mathrm{DDT},{ }^{13} \mathrm{C} 4,4^{\prime} \mathrm{DDD}$, ${ }^{13} \mathrm{C}-4,4$ DDE, ${ }^{13} \mathrm{C}-\alpha-\mathrm{HCH},{ }^{13} \mathrm{C}-\mathrm{HCB}$, and ${ }^{13} \mathrm{C}$-dieldrin $\left(2 \mu \mathrm{g} \cdot \mathrm{mL}^{-1}\right.$ each, in cyclohexane) prepared from solutions purchased from Cambridge Isotope Laboratories (Tewksbury, Massachusetts, USA) were used.

\subsection{Preparation of Model Soils}

Model soils were generated from compost (TOC $=16.1 \%$, finished compost from green waste, dry fermentation), spiked com-post, and RefeSol 01 A [19] (TOC $=0.9 \%$, silty sand) (Table 1 ). The raw materials were proven to be free of target analytes. TOC contents of the model soils were adjusted to represent the most common soil types in Germany [20]. The model soils were spiked to contamination levels derived from the Federal Soil Protection and Contaminated Sites Ordinance [21] using the chemicals compiled in Table 2. 
Table 1. Components of model soils and resulting TOC.

\begin{tabular}{cccc}
\hline $\begin{array}{c}\mathrm{m} \\
\text { (spiked compost)/g }\end{array}$ & $\mathrm{m}$ (RefeSol 01-A)/g & $\mathrm{m}$ (compost)/g & $\begin{array}{c}\text { TOC/\% } \\
\text { (measured value) }\end{array}$ \\
\hline 50 & 2274 & 76 & $1.6 \pm 0.2$ \\
50 & 1654 & 696 & $5.0 \pm 0.5$ \\
50 & 910 & 1440 & $9.2 \pm 0.5$ \\
50 & 166 & 2184 & $13.3 \pm 0.4$ \\
\hline
\end{tabular}

Table 2. Chemicals used during the study and spike level in the resulting model soils.

\begin{tabular}{|c|c|c|c|c|}
\hline chemical & manufacturer & purity & $\begin{array}{c}\text { spike level/ } \\
(\mathrm{mg} / \mathrm{kg})\end{array}$ & $\begin{array}{c}\text { assigned } \\
\text { analyte } \\
\text { group }\end{array}$ \\
\hline $2,4^{\prime}$-DDT & LGC & $99.8 \%$ & 7.07 & \\
\hline $4,4^{\prime}-\mathrm{DDD}$ & LGC & $99.0 \%$ & 8.38 & \\
\hline $4,4^{\prime}-\mathrm{DDE}$ & Fluka & Pestanal & 5.38 & DDX \\
\hline $4,4^{\prime}-\mathrm{DDT}$ & Riedel de Haen & $99.0 \%$ & 10.28 & \\
\hline methoxychlor & Fluka & Pestanal & 4.91 & \\
\hline aldrin & LGC & $97.0 \%$ & 3.17 & \\
\hline dieldrin & LGC & $98.4 \%$ & 2.54 & \\
\hline$\alpha$-endosulfan $(\alpha$-ES) & Riedel de Haen & $99.0 \%$ & 6.40 & \\
\hline hexachlorobenzene (HCB) & Riedel de Haen & $99.0 \%$ & 5.89 & \\
\hline$\alpha$-hexachlorocyclohexane $(\alpha-\mathrm{HCH})$ & Riedel de Haen & $98.0 \%$ & 2.60 & \\
\hline$\beta$-hexachlorocyclohexane $(\beta$-HCH $)$ & Riedel de Haen & $98.4 \%$ & 1.74 & $\mathrm{HCH}$ \\
\hline$\gamma$-hexachlorocyclohexane $(\gamma-\mathrm{HCH})$ & LGC & $99.9 \%$ & 3.98 & \\
\hline РCB 28 & LGC & $99.0 \%$ & 0.28 & \\
\hline PCB 52 & LGC & $99.5 \%$ & 0.23 & \\
\hline РCB 101 & LGC & $99.0 \%$ & 0.42 & \\
\hline PCB 118 & LGC & $99.5 \%$ & 0.38 & РCB \\
\hline PCB 138 & LGC & $98.5 \%$ & 0.24 & \\
\hline РCB 153 & LGC & $99.0 \%$ & 0.17 & \\
\hline РCB 180 & LGC & $99.0 \%$ & 0.27 & \\
\hline
\end{tabular}

\subsection{Spiking}

OCPs and PCBs were dissolved in acetone $(100 \mathrm{ml})$ and added to a slurry of compost $(200 \mathrm{~g}, \leq 2 \mathrm{~mm}$ ) and acetone. The mixture was covered with aluminium foil and left to evaporate at room temperature for two weeks.

The spiked compost was divided into four parts of equal weight and blended with different amounts of unspiked compost and RefeSol $01 \mathrm{~A}$ to yield model soils of different total organic carbon content and the same OCP and PCB content (Table 1).

\subsection{Total Organic Carbon}

All measurements were performed by P. Hoelzmann (Freie Universität Berlin) 
according to the method published by Vogel et al. [22]. The soil TOC content (Table 1) was determined by subtraction of total inorganic carbon from total carbon of the respective soil. In brief, the total carbon content of the samples was determined using combustion with pure oxygen at $950^{\circ} \mathrm{C}$ and quantification of evolving carbon dioxide by infrared technology. For total inorganic carbon evaluation, samples were mixed with hot phosphoric acid and produced carbon dioxide was detected.

\subsection{Material Homogeneity}

The soils were mixed with a drum hoop mixer (ELTE 650/RGM, J. Engelsmann AG, Ludwigshafen, Germany) for $24 \mathrm{~h}$ and homogenised using the cross-riffling procedure (sample divider PT100, Retsch Technology GmbH, Haan, Germany). Of the resulting 56 bottles (content around $42 \mathrm{~g}$ soil each), four were chosen for inter- and intra-bottle homogeneity testing. Every bottle was analysed in triplicate using solid-liquid-extraction (SLE) in accordance with DIN 10382 (see section 2.7) and detection by GC-MS. Homogeneity was assessed using ANOVA.

\subsection{Stability}

During the project, stability of the materials was checked by analysing a control sample every week. For this purpose, $10 \mathrm{~g}$ of the soil with 9.2\% TOC were extracted in accordance with DIN ISO 10382 (Table 3). The median recovery after 50 days was $93.9 \%$ and thus, materials were judged stable during the period of investigation.

\subsection{Analysis}

\subsubsection{Extraction}

PLE, Soxhlet extraction (Sox), as well as variations of SLE were evaluated. All glassware was rinsed with cyclohexane and acetone before experiments. For every analysis, $10 \mathrm{~g}$ of soil spiked with $500 \mu \mathrm{l}$ of internal standard solution (concentration see 2.1) prior to extraction were used. Extraction parameters are summarised in Table 3.

Table 3. Overview of applied extraction methods.

\begin{tabular}{|c|c|c|}
\hline Method & Solvent & Parameters \\
\hline $\begin{array}{l}\text { Pressurised liquid } \\
\text { extraction (PLE) }\end{array}$ & acetone/cyclohexane $2 / 1 \mathrm{v} / \mathrm{v}$ & $\begin{array}{c}2 \text { cycles, } 100^{\circ} \mathrm{C}, 140 \text { bar, } 10 \\
\text { min stationary phase }\end{array}$ \\
\hline Soxhlet extraction (Sox) & $\begin{array}{l}\text { acetone/cyclohexane } \\
1 / 1 \mathrm{v} / \mathrm{v}(100 \mathrm{ml})\end{array}$ & $6 \mathrm{~h}$ \\
\hline DIN 10382 (SLE) & $\begin{array}{c}1 \mathrm{x} \text { acetone }(50 \mathrm{ml}, 15 \mathrm{~min}) \\
2 \mathrm{x} \text { cyclohexane }(50 \mathrm{ml}, 15 \mathrm{~min})\end{array}$ & agitation at $300 \mathrm{~min}^{-1}$ \\
\hline Variants of SLE & $\begin{array}{c}1 \mathrm{x} \text { acetone }(50 \mathrm{ml}, 15 \mathrm{~min}) \\
1 \mathrm{x} \text { cyclohexane }(50 \mathrm{ml}), \\
1 \mathrm{x} \text { rinse with cyclohexane }(50 \mathrm{ml})\end{array}$ & $\begin{array}{c}\text { length of second step varied } \\
\text { between } 1,3,6 \text {, or } 16 \mathrm{~h} \text {, } \\
\text { agitation at } 300 \mathrm{~min}^{-1}\end{array}$ \\
\hline
\end{tabular}




\subsubsection{Pressurised Liquid Extraction (PLE)}

A soil sample was weighed into a $22 \mathrm{ml}$ PLE-cell and internal standard was added. Subsequently, the sample was extracted according to the procedure noted in Table 3 using a Dionex ASE 200 (Thermo Scientific, Sunnyvale, CA, USA). The following procedure was carried out for all samples, regardless of the applied extraction technique: Obtained extracts were washed with deionised water $(2 \times 400$ $\mathrm{ml}$ ), dried over sodium sulfate, and concentrated to $5 \mathrm{ml}$ using a Turbo Vap II (Biotage Concentration Workstation, Uppsala, Sweden). An aliquot of $100 \mu \mathrm{l}$ underwent the clean-up procedure.

\subsubsection{Soxhlet Extraction (Sox)}

Internal standard was added to a soil sample weighed into an extraction thimble (MN645, $33 \times 80$ mm idxh, Macherey-Nagel GmbH \& Co. KG, Düren, Germany). After placing the thimble in a Soxhlet apparatus the solvent mixture was added to the equipped $250 \mathrm{ml}$ round-bottom flask. The solvent was then heated to reflux. Extraction parameters can be found in Table 3. After extraction was completed the obtained extract was treated as described for PLE.

\subsubsection{Solid-Liquid Extraction According to DIN ISO 10382}

A soil sample, internal standard, and acetone $(50 \mathrm{ml})$ were put into a $250 \mathrm{ml} \mathrm{Er}$ lenmeyer flask. After $15 \mathrm{~min}$ of agitation $\left(300 \mathrm{~min}^{-1}\right.$, horizontal shaker HS501 digital, IKA Werke GmbH \& Co. KG, Staufen, Germany) a portion of cyclohexane $(50 \mathrm{ml})$ was added. Following an extraction period of another $15 \mathrm{~min}$, the supernatant was decanted into a $1 \mathrm{~L}$ separating funnel. To the soil cyclohexane $(50 \mathrm{ml})$ was added and it was extracted again for $15 \mathrm{~min}$. Finally, the organic extracts were combined and treated further as explained for PLE.

\subsubsection{SLE Variants}

A soil sample was weighed into a $250 \mathrm{ml}$ Erlenmeyer flask and internal standard as well as acetone $(50 \mathrm{ml})$ were added. After agitation for $30 \mathrm{~min}$ cyclohexane $(50 \mathrm{ml})$ was added and the mixture was extracted for 1, 3, 6 or 16 hours (Table 3). Subsequently, the supernatant was decanted into a $1 \mathrm{~L}$ separating funnel and the extract was washed as mentioned for PLE.

\subsubsection{Clean-Up Procedure}

Prior to use, aluminium oxide (neutral, activity Super I, J. T. Baker, Avantor Performance Materials B. V., Deventer, The Netherlands) was heated to $150^{\circ} \mathrm{C}$ for five hours and left to cool in a desiccator. Subsequently, the dried aluminium oxide was deactivated using $10 \mathrm{wt} \%$ water. After storing in the absence of air for one day it was ready to use.

For solid phase extraction clean-up, $2 \mathrm{~g}$ of deactivated aluminium oxide were weighed into a $6-\mathrm{ml}$ glass cartridge equipped with a polyethylene frit. An aliquot of the extract was added to the dry aluminium oxide and eluted with $20 \mathrm{ml}$ of cyclohexane. The cleaned extract was concentrated to $1 \mathrm{ml}$ under nitrogen and transferred into a GC-vial. Prior to measurement, $100 \mu \mathrm{l}$ of injection standard (PCB 198) were added. 


\subsubsection{GC-MS Measurements}

GC-MS analysis was competed using an Agilent GC 6890, MSD 5973N (Agilent Technologies, Waldbronn, Germany) with a HT 8 column (50 m, $0.22 \mathrm{~mm}$ i.d., $0.25 \mu \mathrm{m}$ f.t.) (SGE Analytical Science, Ringwood, Australia). The carrier gas was helium (He 5.0) at a flowrate of $1 \mathrm{ml} / \mathrm{min}$. The injector was split/splitless, $1 \mu \mathrm{l}$ of sample was injected with a split flow $20 \mathrm{ml} / \mathrm{min}$ at $1 \mathrm{~min}$. The oven was programmed with an initial hold of $1 \mathrm{~min}$ at $50^{\circ} \mathrm{C}$, followed by a ramp of $50^{\circ} \mathrm{C} / \mathrm{min}$ to $168^{\circ} \mathrm{C}$, a second ramp of $4^{\circ} \mathrm{C} / \mathrm{min}$ to $310^{\circ} \mathrm{C}$, and a final hold time of $15 \mathrm{~min}$. The mass spectrometer parameters were $\mathrm{EI} 70 \mathrm{eV}$, selected ion mode (SIM), with a solvent delay of 6 minutes.

\begin{tabular}{|c|c|}
\hline Instrument & $\begin{array}{l}\text { Agilent GC 6890, MSD 5973N } \\
\text { (Agilent Technologies, Waldbronn, Germany) }\end{array}$ \\
\hline Carrier Gas & He $5.0,1 \mathrm{ml} / \mathrm{min}$ \\
\hline MSD Parameters & EI $70 \mathrm{eV}$, selected ion mode (SIM), solvent delay 6 min \\
\hline Injection & split/splitless injector, $1 \mu \mathrm{l}$, split flow $20 \mathrm{ml} / \mathrm{min} @ 1 \mathrm{~min}$ \\
\hline Liner & $\begin{array}{l}\text { glass liner, baffled and deactivated } \\
\text { (Gerstel GmbH \& Co. KG, Mühlheim an der Ruhr, Germany) }\end{array}$ \\
\hline Column & $\begin{array}{c}\mathrm{HT} 8,50 \mathrm{~m}, 0.22 \mathrm{~mm} \text { inner diameter, } 0.25 \mu \mathrm{m} \text { film thickness (SGE } \\
\text { Analytical Science, Ringwood, Australia) }\end{array}$ \\
\hline Oven Programme & $\begin{array}{c}1 \mathrm{~min} \text { at } 50^{\circ} \mathrm{C} \text {, with } 50^{\circ} \mathrm{C} / \mathrm{min} \text { to } 168^{\circ} \mathrm{C} \text {, with } 4^{\circ} \mathrm{C} / \mathrm{min} \text { to } 310^{\circ} \mathrm{C} \text {, } \\
15 \mathrm{~min} \text { at } 310^{\circ} \mathrm{C}\end{array}$ \\
\hline PTV & $\begin{array}{l}\text { Gerstel KAS } 4 \text { (Gerstel GmbH \& Co. KG, Mühlheim an der Ruhr, } \\
\text { Germany) }\end{array}$ \\
\hline
\end{tabular}

\subsection{Quality Assurance}

Prior to the start of the extractions of the model soils, a certified reference material (ERM-007a) was analysed in accordance with DIN ISO 10382 to ensure adequate operation of methodology.

All extractions were carried out in quadruplicate. One control sample was analysed every week (section 2.2). The average standard deviation of compound concentrations in the control samples was $13.5 \%$ while the same value in the homogeneity studies was $8.1 \%$.

The initial calibration used 12 points in the linear working range $(0.01-5 \mu \mathrm{g})$. Two points were recalibrated during every measurement sequence. The measurement system performance was checked by evaluation of the area of the signal of PCB 198 (injection standard). The GC-liners were replaced in between runs or after a maximum of 100 injections. A blank value (solvent only) was measured after every sample run to ensure that carry-over was not significant.

\subsection{Statistics}

Normality, skewness, and kurtosis tests were run on the data. Outliers were identified using Grubbs' test. These data were in-formational only and outliers have been retained as a characteristic for the soil type or the method used. Basic 
statistic values including mean, median, standard deviation of the mean, and median absolute deviation as the dispersion estimate for the median were calculated. Hierarchical cluster analysis versus the extraction method was carried out. Euclidian distances and Ward linkage were used.

The above was carried out for any analyte under consideration separately, for groups of chemically similar behaving analytes, and all results of the study (see correspondingly sections 3.1 to 3.3 of this paper). As long as different analyte levels had to be combined or compared, statistical analysis referred to normalised values, i.e. recovery rates obtained from normalisation against the spiked values.

Recovery rates were calculated using measurement results and the gravimetric data for spiking, treated as above, and dis-played in graphs as shown (for the low-level TOC) under Figure 2.

Cluster analysis aimed at defining the best extraction procedure (assessed by the recovery rate) and included all analytes not (overwhelmingly) restricted (recoveries above $100 \%$ or clearly not normal data distribution). For the graph shown under Figure 4, analytes showing these peculiarities have been excluded, namely PCB 28, 52, 138; dieldrin, and methoxychlor.

\section{Results and Discussion}

In order to perform the data analysis in an extensive, yet comprehensible way a simplification approach was used. At first, the recovery of all analyte groups was evaluated separately in each soil and for each extraction method. As a next step, the results were judged independently of the different soil matrices. Finally, the data were reviewed for all analytes and matrices combined.

\subsection{Analyte Group Specific Evaluation}

Since the spiked PCBs vary only slightly in their structure, they were expected to behave quite similarly during extraction and clean-up. The OCPs however are a much more diverse group. They differ greatly in polarity, stability, and volatility [24]. Hence, uniform extraction behaviour was not expected and an evaluation focussing on the different substance classes was thought to be more helpful.

\subsubsection{Dependence on Soil Type}

Several studies have confirmed the assumption that the soil TOC content has a major influence on the extractability of organic pollutants [23] [25] [26]. Therefore it was expected that the analyte recoveries from the model soil with $1.6 \%$ TOC would surpass those from the soil with $13.3 \%$ TOC, independently of the employed extraction method. Figure 1(a) shows the recovery of HCB from the different soils. The extraction methods which were used are represented as grey columns which are grouped in such a way as to illustrate their affiliation to a certain model soil. The recoveries for HCB lie between $(62 \% \pm 12 \%)(1.6 \%$ TOC, $6 \mathrm{~h}$ agitation SLE) and (107\% $\pm 7 \%)(5.0 \%$ TOC, PLE). Concerning pesticide analysis, these values are generally considered acceptable [14] [27]. The highest mean recovery values are achieved for the soils with 5.0\% und 9.2\% TOC. How- 

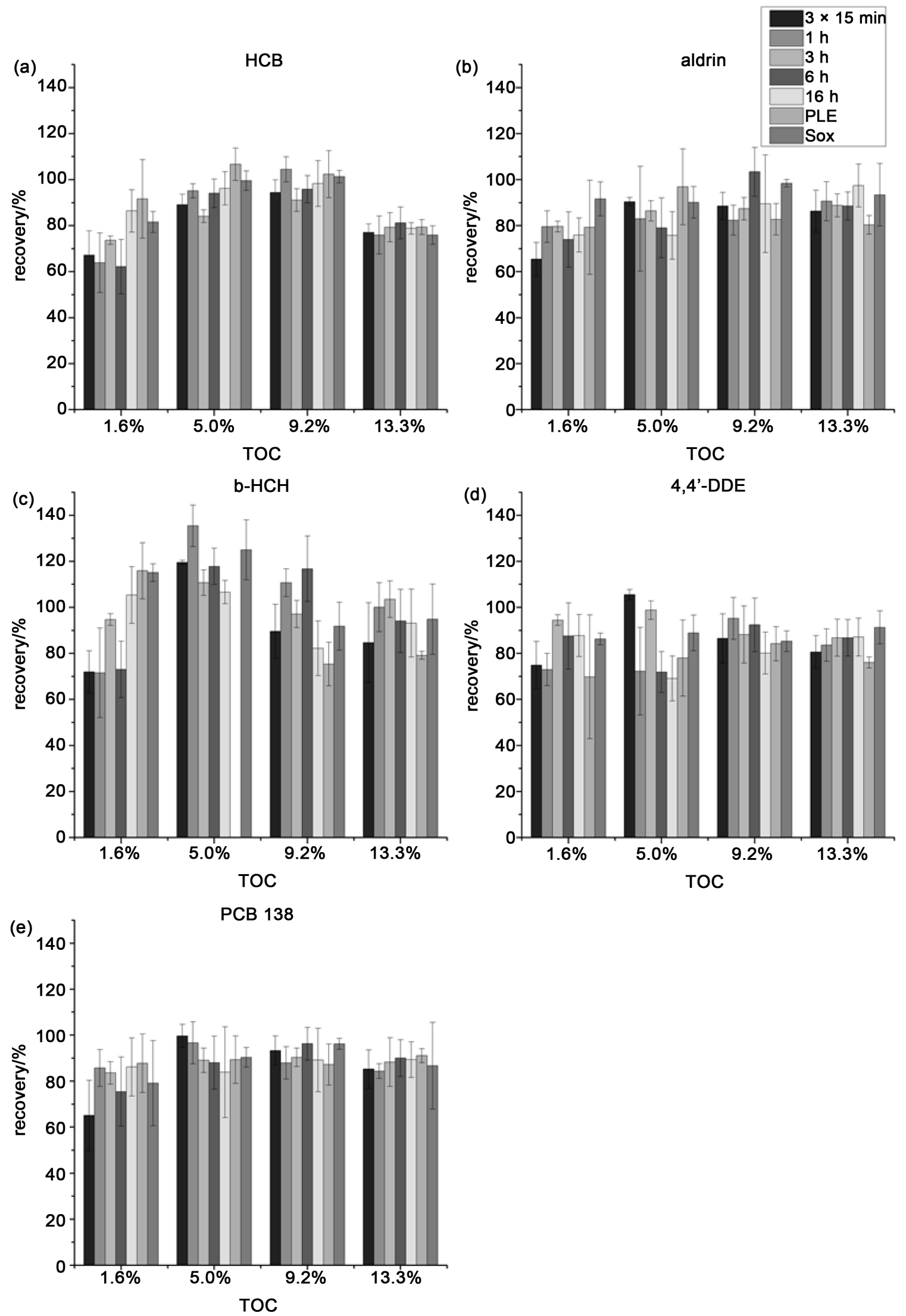

Figure 1. Recovery of the analytes (a) HCB, (b) aldrin, (c) $\beta$-HCH, d) 4,4'-DDE, and (e) PCB 138 in \% of spiked concentration. The error bars indicate the standard deviation $(n=4)$. 
ever, the mean values and standard deviations calculated for each separate extraction method are most similar for the soil of highest TOC and they differ the most for the soil with low TOC. In the latter case prolonged extraction time and more drastic conditions (PLE, Soxhlet extraction) lead to higher HCB recovery. Nevertheless, none of these variations are statistically significant and no general rule can be deduced. Of all the analytes which were evaluated the standard deviations are always lowest for HCB as it can be very well measured using a GC MS system. This is also the reason why HCB is sold as a com-pound on which to judge system performance.

Concerning the analyte aldrin (Figure $1(\mathrm{~b})$ ), the results are fairly similar. Overall, a minimum recovery of $(65 \% \pm 7 \%)(1.6 \%$ TOC, $3 \times 15$ min agitation SLE) and maximum of $(103 \% \pm 11 \%)(9.2 \%$ TOC, $6 \mathrm{~h}$ agitation SLE) were achieved. The mean extraction efficiencies do however not differ as much as for HCB. Regardless, the differences between extraction methods are also not statistically significant. In the case of aldrin it has to be noted that it is known to degrade into its epoxy analogue dieldrin very quickly [28] [29]. As a comparison with the values obtained for dieldrin recovery showed (data not displayed) it is possible that part of the aldrin has already been converted. This is also supported by comparing median values of all recoveries for aldrin and dieldrin. The median of aldrin (87\%) is lower than the median for Dieldrin (107\%).

In the case of the $\mathrm{HCH}$ group (Figure 1(c)) findings do not differ much from those described for the other analytes. It is however noticeable that the standard deviations are higher (up to 19\%) and the recoveries are the lowest in case of the model soil with $1.6 \%$ TOC content (compare HCB). For this matrix slightly better recoveries are achieved as well when the SLE time is longer or a more intense method like Soxhlet extraction or PLE is used.

As a representative of the group of DDT, its metabolites, and related compounds (henceforth called DDX), the graph for 4,4' DDE is shown (Figure $1(\mathrm{~d}))$. Recovery rates range from $(69 \% \pm 10 \%)(5.0 \%, 16 \mathrm{~h}$ agitation SLE) to $(106 \% \pm 2 \%)(5.0 \%$ TOC, $3 \times 15$ min agitation SLE). A clear dependency of recovery on soil type cannot be determined. 4,4' DDE is the most stable of the DDT metabolites. For the other DDX, high overestimations were found in some cases ( $>140 \%$, data not considered).

This instance is illustrated in Figure 2 in which the recoveries for all analytes in the low-level TOC model soil can be found. Concerning the $3 \times 15$ minute and 1 hour SLE, the recovery values of most analytes are below 1 . This is the generally ex-pected case, as the total analyte content may not be available for extraction due to formation of NER. With a longer extraction period (16 hours) or the use of Soxhlet extraction the apparent recovery of the DDX increases drastically to levels above $100 \%$. This increase is attributed to analyte decomposition [30] and matrix enhancement effects [31] in the GC liner. This is reasonable as a proplonged extraction time or the use of an intense extraction method like Soxhlet also promotes the extraction of unwanted matrix. This matter is further discussed in Section 3.3. 

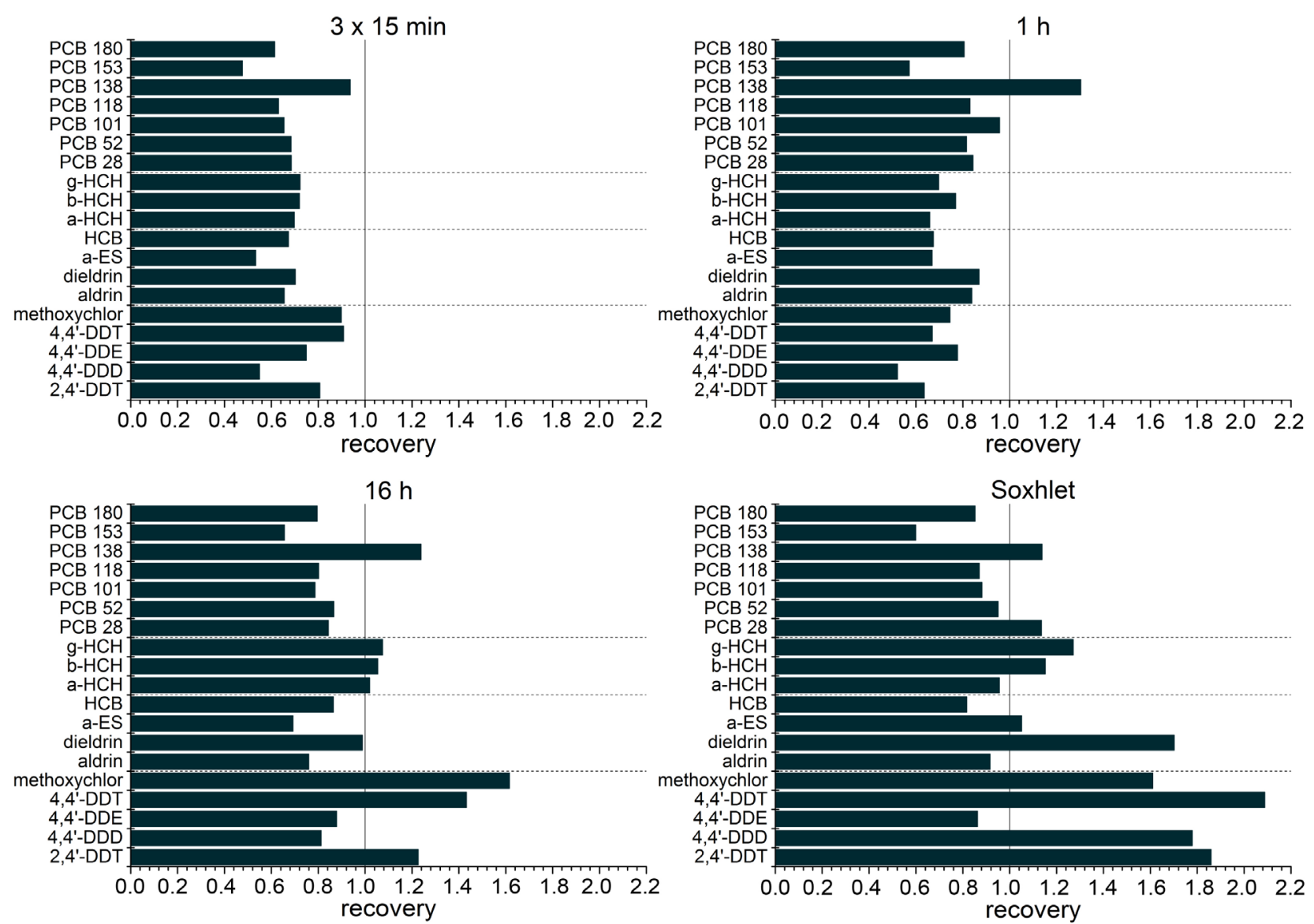

Figure 2. Recoveries as assessed for the measurands under consideration in the low-level TOC soil using SLE with $3 \times 15 \mathrm{~min}, 1 \mathrm{~h}$, $16 \mathrm{~h}$ and Soxhlet extraction. All "explainable" values are below the unity line (recovery = 1), all unexpected above.

Judging from the data obtained during this study PCBs do not seem to be a point of concern during SLE from soils. The data for PCB 138 are shown in Figure $1(\mathrm{e})$. A connection between longer agitation times and higher recoveries cannot be found in this case.

Considering all the results, it can be concluded that the analyte recovery is not significantly dependent on the TOC content of the model soils used in this study. No relationship can be observed. Of course, fluctuations in recovery cannot solely be attributed to this soil property [32]. Regardless, it was unexpected how little impact the TOC content seemed to have. It has been discussed before that the type of organic matter which makes up the TOC content has a greater impact on NER formation and extractability of pollutants [33]. Concerning OCPs and PCBs especially the aromaticity of soil organic matter should have an influence on analyte recovery [34]. A detailed characterisation of the soil organic matter in the model soils could lead to some insight.

\subsubsection{Dependence on Extraction Method}

The first approach towards data analysis showed that analyte recovery is in general not dependent on the model soil TOC. Therefore, to find out if the extraction time and method have an effect on the substance recovery the data were 

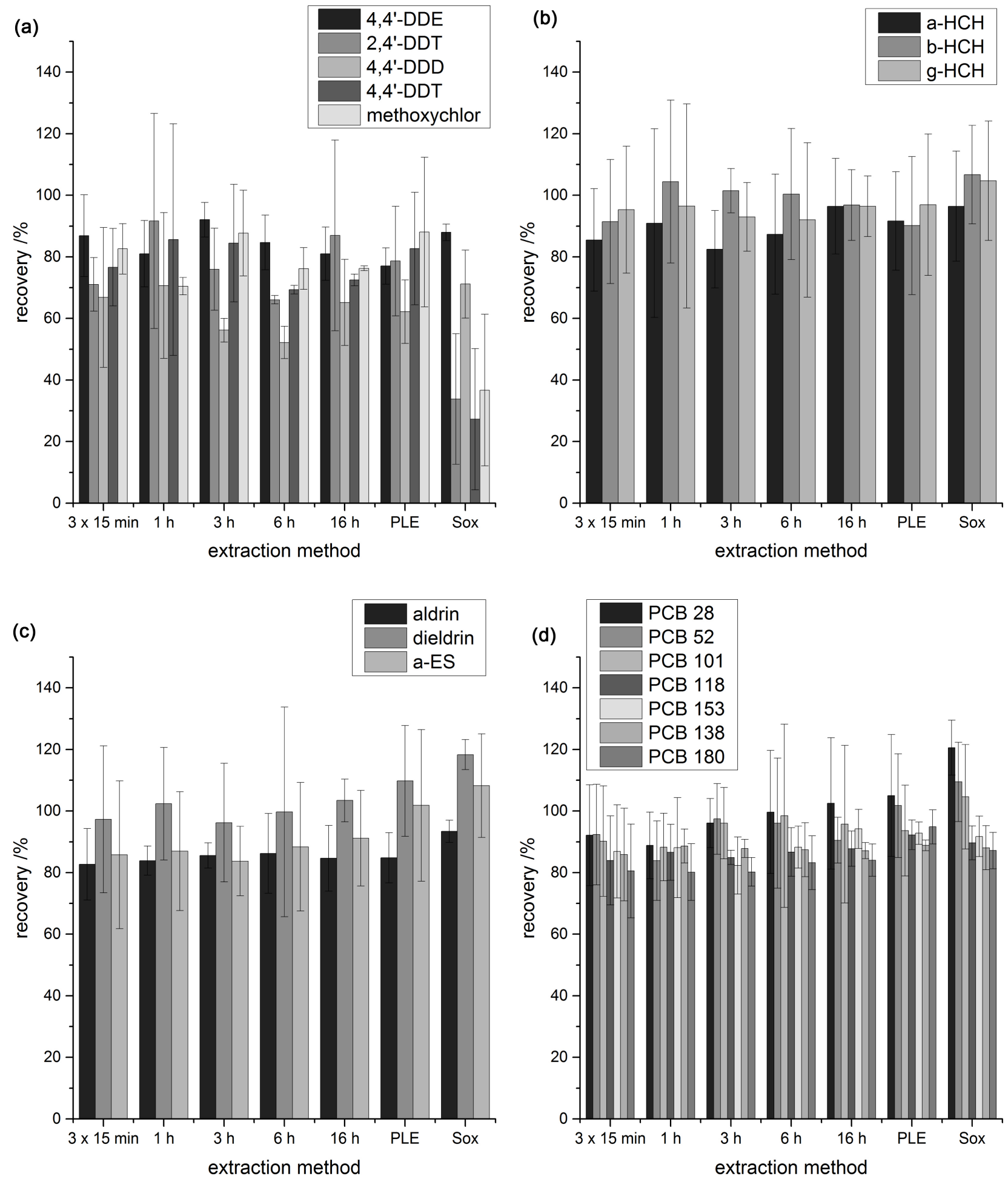

Figure 3. Recovery of (a) DDX, (b) HCH, (c) aldrin, dieldrin, and $\alpha$-ES, and (d) PCB in \% of spiked concentration using different extraction techniques. The error bars indicate the standard deviation $(\mathrm{n}=4)$.

re-evaluated independent of the amount of soil organic matter. Figure 3(a) shows the mean recovery over all soils of the DDX for different extraction techniques. A clear trend is not immediately recognisable. For SLE, the recoveries lie between $(52 \% \pm 5 \%)\left(4,4^{\prime}\right.$ DDD, 6 h agitation SLE) and $(92 \% \pm 6 \%)\left(4,4^{\prime}\right.$ DDE, 3 
$\mathrm{h}$ agitation SLE). The degradation products of DDT, 4,4' DDE and 4,4' DDD, generally show acceptable recovery for all extraction methods. With recoveries as low as $27 \%$ of the spiked concentration, the use of Soxhlet is not suitable for extraction of 2,4' DDT, 4,4' DDT, and methoxychlor. This can be associated with the thermolability of these analytes which leads to degradation during the extraction cycles [35]. The comparably low recovery of DDX using Soxhlet has already been noted by several researchers [36]. Surprisingly, Soxhlet extraction is widely used for these analytes. The standard deviations for all DDX except 4,4' DDE are relatively high, up to $38 \%$. This can be attributed to the condition of the GC liner and is discussed in Section 3.3.

The extraction of the $\mathrm{HCH}$ (Figure 3(b)), aldrin, dieldrin, and $\alpha$-endosulfan ( $\alpha$ ES) (Figure $3(c)$ ) is possible with all employed ex-traction methods. Recoveries range from $(83 \% \pm 12 \%)$ (aldrin, $3 \times 15 \mathrm{~min}$ SLE) to $(118 \% \pm 5 \%)$ (dieldrin, Soxhlet) with accepta-ble standard deviations. Yet, it is to be noticed that the mean value of dieldrin is higher than that of aldrin for all experiments. A possible explanation for this effect might be the conversion of aldrin into the more stable dieldrin in soils (see above) [28]. In literature there are already some studies available which deal with a comparison of OCP extraction from soils using different techniques. Most of them focus on Soxhlet, PLE, ultrasonic-assisted extraction, and microwave-assisted extraction, which are not found to differ much in extraction efficiency [37]. Our study is able to show that SLE also performs satisfactory.

Concerning the PCBs (Figure 3(d)) a review of the data does not give a most favourable extraction method, either. Admittedly, the mean recovery of the PCBs with less chlorine substituents seems to increase slightly when the agitation time is longer. Since PCBs are considered very thermostable, Soxhlet is also applicable and yield satisfying results. Previously published studies have also shown that results from Soxhlet extraction, PLE, and microwave-assisted extraction are usually comparable for PCBs [38] [39] [40]. In the standard EN 16167 [41] which describes the extraction of PCBs from sludge, treated biowaste, and soil the duration of the SLE is required to be 12 hours. The results of our study do however demonstrate that such a long extraction is not necessary for the matrix soil.

In summary, no preferred extraction method for any analyte group could be identified. The results of this study do not lead to the assumption that prolonged SLE time leads to better recovery. This is supported by cluster analysis as shown in Figure 4. There are clearly two groups differing from each other. The second group encompasses all extractions of the $13.3 \%$ TOC soil. As for the other soils, no clear assignment to one group is evident. The same holds for the different extraction methods. Hence, an extraction method with superior performance cannot be identified.

\subsection{Evaluation for Total Analyte Spectrum}

Ideally, OCPs and PCBs should be extracted together with one suitable method. All in all, the review of the experimental data so far has led to the assumption that the recovery of all analytes is more or less the same independent of model 


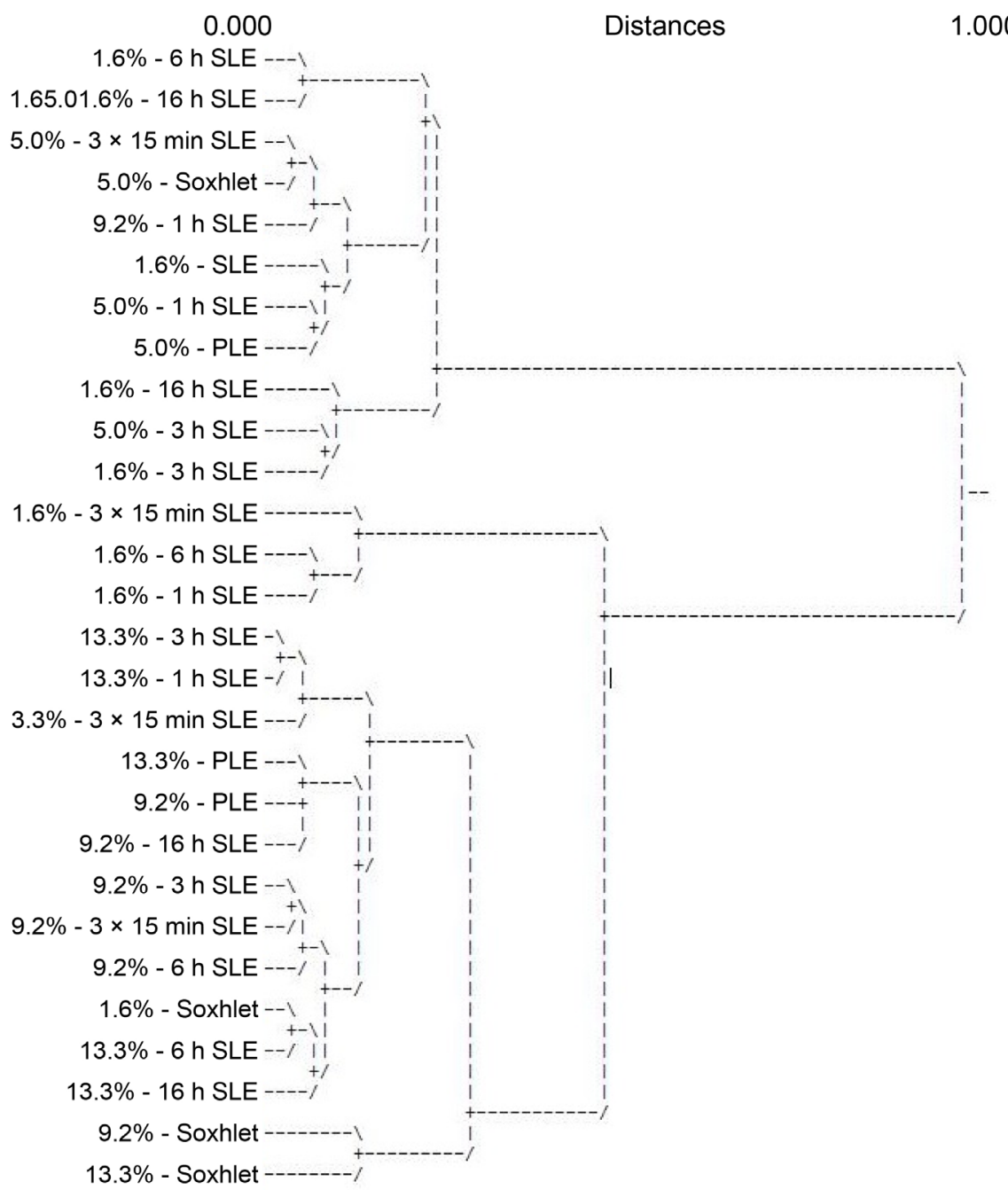

Figure 4. Hierarchical clustering of all data obtained sorted by extraction method (Euclidian distance, Ward linkage).

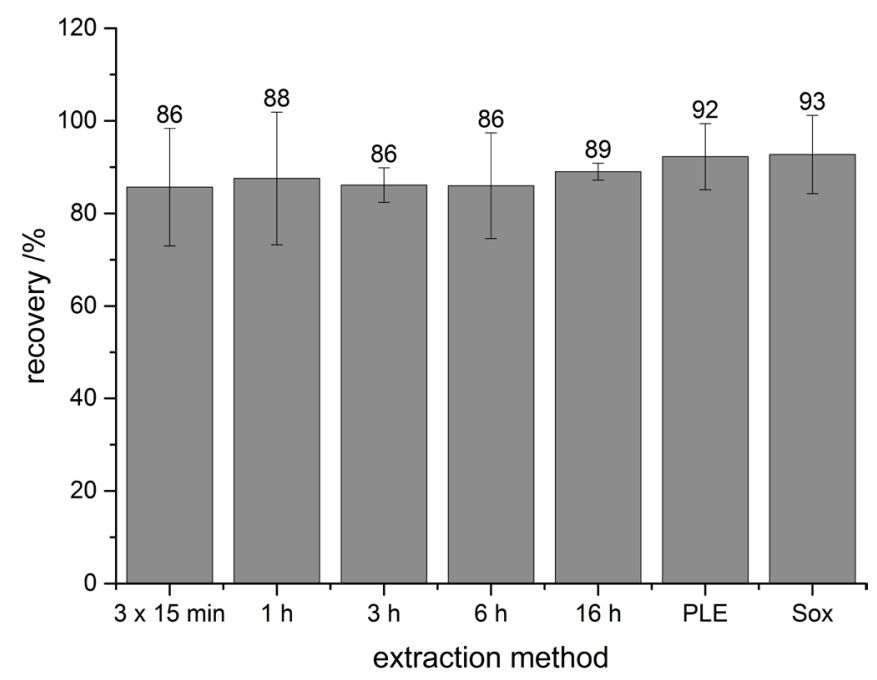

Figure 5. Recovery of all analytes (in \% of spiked concentration) from soils of varying TOC. The error bars indicate the standard deviation over all analytes $(n=19)$ and extractions $(\mathrm{n}=4)$. 
soil TOC content and applied extraction technique. For this reason, the data set was re-evaluated using the mean recoveries of all analytes. To verify the previous results, Figure 5 shows the recoveries for all analytes in dependence of model soil TOC. Generally, all extraction methods give more or less the same results, independent of the soil type. Concerning the soil with the lowest TOC however, prolonged agitation and the use of other extraction techniques lead to higher mean recoveries by about $20 \%$. This has also been noted for single analytes, as described in the previous section. When taking into account the standard deviations which are in the range of $1020 \%$, the t-test at a $95 \%$ confidence level does however give as a result that none of these findings differ significantly. Therefore, it is possible to neglect classification of the data altogether and handle them as a single population. Figure 6 illustrates this approach. The differences in the performance of certain extraction techniques are greatly diminished when all analytes and all model soils are considered simultaneously. Recoveries range from $86 \%(3 \times 15 \mathrm{~min})$ to $93 \%$ (PLE, Sox). The standard deviations exceed the differences between the means by far. Hence, the performance of all extraction methods can be seen as equivalent. The more intense extraction techniques do not lead to a significantly better analyte recovery than SLE. However, they do offer some advantages (Table 4). An analysis done with PLE or Soxhlet requires less solvent and the washing step is facilitated as no matrix particles get into the solvent phase as may be the case during decanting from an Erlenmeyer flask. PLE is also faster and can be automated. Additionally, the manual work load is lower. Nevertheless, PLE and Soxhlet should preferrably be used for the extraction of thermolabile analytes in combination with labelled internal standards (see Sections 3.1 and 3.3). Additonally, they call for trained personnel, whereas SLE is relatively easy to execute.

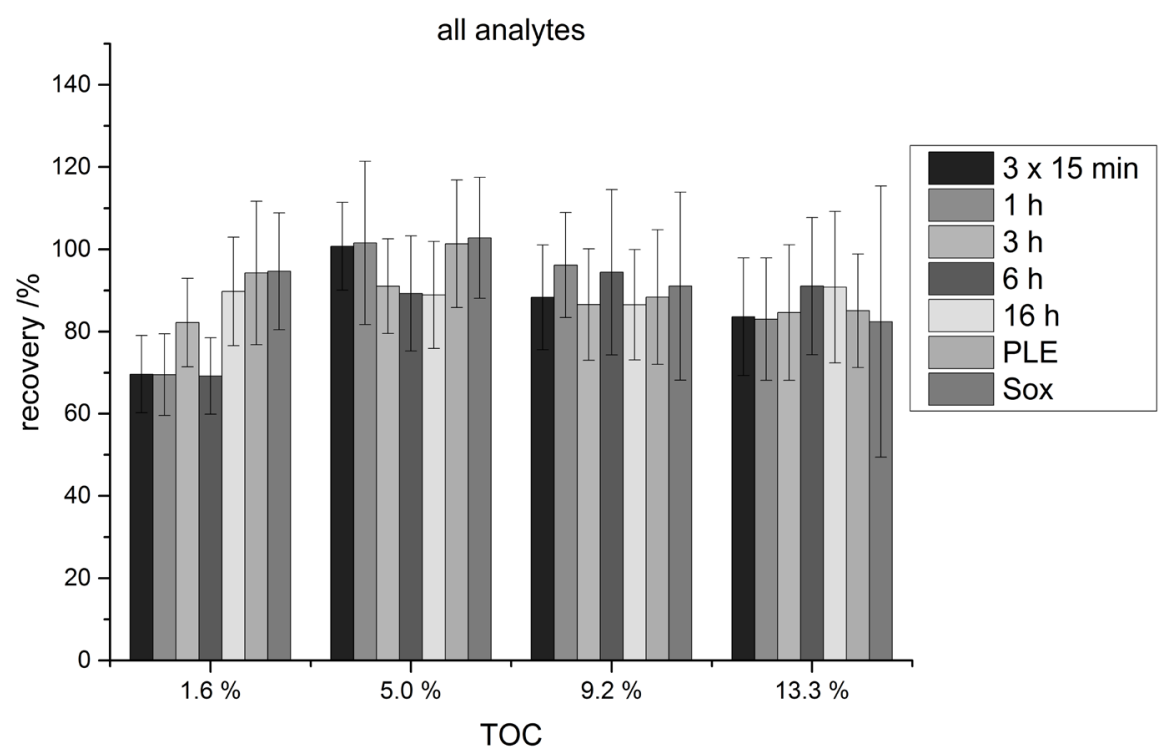

Figure 6. Recovery of all analytes (in \% of spiked concentration) using different extraction techniques. The error bars indicate the standard deviation over all analytes $(n=19)$ and extractions $(\mathrm{n}=4)$. 
Table 4. Advantages and disadvantages of SLE, PLE, and Soxhlet.

\begin{tabular}{|c|c|c|c|}
\hline & SLE & PLE & Soxhlet \\
\hline Compounds & $\begin{array}{c}\text { Suitable for all } \\
\text { tested OCPs and } \\
\text { PCBs }\end{array}$ & $\begin{array}{l}\text { Suitable for all tested } \\
\text { OCPs and PCBs }\end{array}$ & $\begin{array}{l}\text { Only suitable for } \\
\text { thermolabile analytes in } \\
\text { combination with } \\
\text { labelled internal } \\
\text { standards }\end{array}$ \\
\hline $\begin{array}{l}\text { Complexity of } \\
\text { technique }\end{array}$ & $\begin{array}{l}\text { Easy extraction } \\
\text { principle, } \\
\text { washing step } \\
\text { potentially } \\
\text { problematic }\end{array}$ & $\begin{array}{c}\text { Trained personnel } \\
\text { necessary, washing step } \\
\text { uncomplicated }\end{array}$ & $\begin{array}{l}\text { Trained personnel } \\
\text { necessary, washing } \\
\text { step uncomplicated }\end{array}$ \\
\hline $\begin{array}{c}\text { Amount of solvent } \\
\text { per sample }\end{array}$ & $150 \mathrm{ml}$ & $22 \mathrm{ml}$ (PLE) & $100 \mathrm{ml}$ (Sox) \\
\hline $\begin{array}{l}\text { Time consumption } \\
\text { (without clean-up) }\end{array}$ & $\sim 1.5 \mathrm{~h}$ & $\sim 0.5 \mathrm{~h} /$ sample & $\min . \sim 6 \mathrm{~h}(\mathrm{Sox})$ \\
\hline
\end{tabular}

\subsection{Use of Internal Standards and GC Liners}

Undoubtedly, the GC liner has a great influence on the reproducibility of analytical results. Its inertness is of decisive importance, as analytes may adsorb to active sites in the inlet system and are thus lost to analysis [31]. When matrix contami-nated samples are injected, high boiling residues accumulate in the liner [42]. These are known to promote the breakdown of several OCPs, for example endrin and DDT, thereby leading to underestimations [43] [44] [45]. This phenomenon has been used to judge the performance of inert liners and capillary columns [46] [47] [48].

In this study, an unexpected reverse effect was noticed. In several cases the analyte content was greatly overestimated $(>140 \%)$ for the thermolabile DDX and dieldrin. To gain insight into this problem, a soil extract of the campaign was additionally spiked with ${ }^{13} \mathrm{C}$-labelled standards and injected 100 times, starting with a new liner. The results for the thermolabile 4,4' DDT and the thermostable 4,4' DDE are shown in Figure 7. For both analytes the ratio of the native and ${ }^{13} \mathrm{C}$-labelled substance remain more or less the same for all injections. However, when PCB 209 is employed as internal standard it can be noticed that after 100 injections the ratio of 4,4' DDT/PCB 209 has increased by a factor of around 1.5, even though the area of PCB 209 does not decrease. This is not the case for 4,4' DDE: The performance of the labelled standard and PCB 209 is comparable.

Unfortunately, a definite cause of the problem could not be found. However, such an effect is often observed in food analysis where highly matrix-contaminated samples are analysed [31]. This matrix enhancement effect is supposedly caused by active sites in the liner and on the GC column. When a calibration solution in a clean solvent is injected, the analytes may adsorb to these sites leading to signal intensity loss. If a matrix containing sample is injected the matrix components compete with the analytes for adsorption sites, leading to a higher signal intensity and often better peak shape [49]. To overcome this 


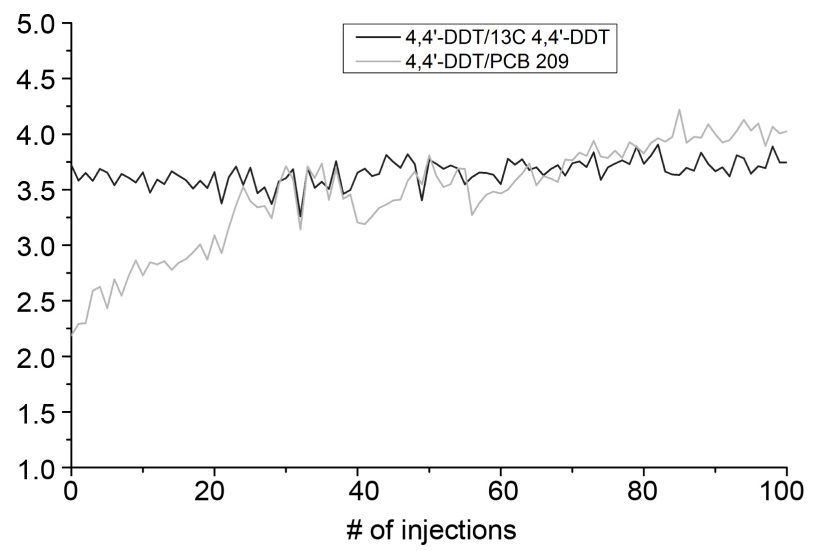

(a)

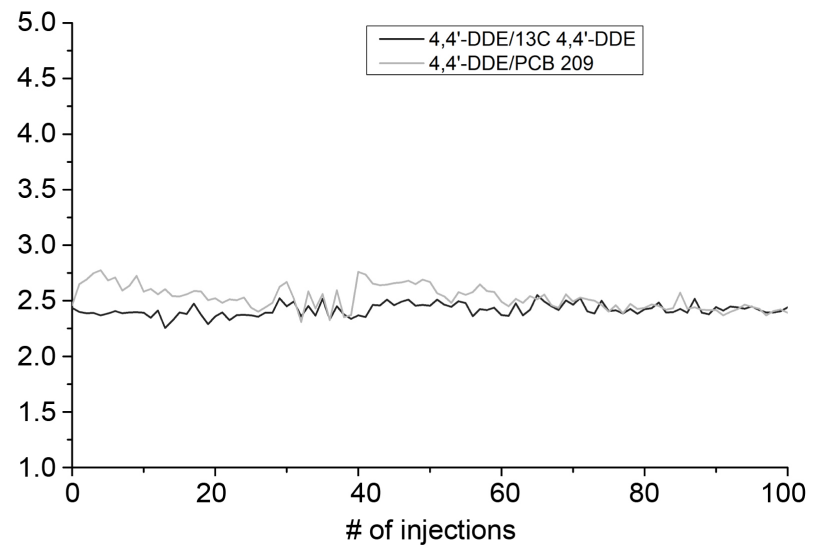

(b)

Figure 7. Ratios of the area of 4,4'-DDT and 4,4'-DDE versus the ${ }^{13} \mathrm{C}$-labelled substances and PCB 209 as internal standard over the course of 100 injections.

problem, it is advisable to use for example matrix calibration, analyte protectants, or labelled standards [50] [51]. The latter may be a simple solution, but high financial cost is associated with this approach. In this study, it could be shown that the use of labelled standards for critical analytes helps to counterbalance changing conditions in the injection system.

\section{Conclusion}

Based on the data obtained during this study, no relation between the TOC content of the model soils and analyte recovery could be identified. Additionally, no clear correlation between the duration of SLE and recovery of analytes could be found. For PLE and Soxhlet extraction, analyte recoveries are comparable to those of SLE. However, the analysis of thermolabile pesticides is only appropriate when used in combination with ${ }^{13} \mathrm{C}$-labelled standards. When taking into account the typically high standard deviations, SLE with short extraction times are also suitable for extraction of PCBs and OCPs from soil. To overcome matrix effects during GC MS measurements it is preferred to use isotopically labelled standards. However, for certain analytes, e.g. PCBs, other internal standards may be applicable.

\section{Acknowledgements}

The authors thank P. Hoelzmann (Freie Universität Berlin) for the TOC measurements and U. Kalbe (BAM) for providing RefeSol and compost.

\section{References}

[1] United Nations Environment Programme (2001) Stockholm Convention on Persistent Organic Pollutants.

[2] Barrie, L.A., Gregor, D., Hargrave, B., Lake, R., Muir, D., Shearer, R., Tracey, B. and Bidleman, T. (1992) Arctic Contaminants: Sources, Occurrence and Pathways. Science of the Total Environment, 122, 1-74.

[3] Muir, D.C.G., Norstrom, R.J. and Simon, M. (1988) Organochlorine Contaminants 
in Arctic Marine Food Chains: Accumulation of Specific Polychlorinated Biphenyls and Chlordane-Related Compounds. Environmental Science \& Technology, 22, 1071-1079. https://doi.org/10.1021/es00174a012

[4] Willett, K.L., Ulrich, E.M. and Hites, R.A. (1998) Differential Toxicity and Environmental Fates of Hexachlorocyclohexane Isomers. Environmental Science \& Technology, 32, 2197-2207. https://doi.org/10.1021/es9708530

[5] United Nations Environment Programme (2007) Global Monitoring Plan on Persistent Organic Pollutants.

[6] Bollag, J.M. and Loll, M.J. (1983) Incorporation of Xenobiotics into Soil Humus. Experientia, 39, 1221-1231. https://doi.org/10.1007/BF01990359

[7] Haider, K., Spiteller, M., Reichert, K. and Fild, M. (1992) Derivatization of Humic Compounds: An Analytical Approach for Bound Organic Residues. International Journal of Environmental Analytical Chemistry, 46, 201-211. https://doi.org/10.1080/03067319208027010

[8] Roberts, T.R. (1984) Non-Extractable Pesticide Residues in Soils and Plants. Pure and Applied Chemistry, 56, 945-956. https://doi.org/10.1351/pac198456070945

[9] Gevao, B., Semple, K.T. and Jones, K.C. (2000) Bound Pesticide Residues in Soils: A Review. Environmental Pollution, 108, 3-14.

[10] Barriuso, E., Benoit, P. and Dubus, I.G. (2008) Formation of Pesticide Nonextractable (Bound) Residues in Soil: Magnitude, Controlling Factors and Reversibility. Environmental Science \& Technology, 42, 1845-1854.

https://doi.org/10.1021/es7021736

[11] Gevao, B., Jones, K.C. and Semple, K.T. (2005) Formation and Release of Non-Extractable 14C-Dicamba Residues in Soil under Sterile and Non-Sterile Regimes. Environmental Pollution, 133, 17-24.

[12] Scheunert, I. and Schroder, P. (1998) Formation, Characterization and Release of Non-Extractable Residues of $\left[{ }^{14} \mathrm{C}\right]$-Labeled Organic Xenobiotics in Soils. Environmental Science and Pollution Research, 5, 238-244.

https://doi.org/10.1007/BF02986407

[13] Barriuso, E., Houot, S. and SerraWittling, C. (1997) Influence of Compost Addition to Soil on the Behaviour of Herbicides. Pest Management Science, 49, 65-75. https://doi.org/10.1002/(SICI)1096-9063(199701)49:1<65::AID-PS488>3.0.CO;2-Z

[14] Nestler, A. (2007) Bestimmung der Messunsicherheit für die Verfahren und Methoden zur Bodenanalytik des Anhangs 1 der Bundes-Bodenschutz- und Altlastenverordnung. Ph.D. Thesis, Freie Universität, Berlin.

[15] Li, Y.F. and Macdonald, R.W. (2005) Sources and Pathways of Selected Organochlorine Pesticides to the Arctic and the Effect of Pathway Divergence on $\mathrm{HCH}$ Trends in Biota: A Review. Science of the Total Environment, 342, 87-106.

[16] Bakore, N., John, P.J. and Bhatnagar, P. (2004) Organochlorine Pesticide Residues in Wheat and Drinking Water Samples from Jaipur, Rajasthan, India. Environmental Monitoring and Assessment, 98, 381-389. https://doi.org/10.1023/B:EMAS.0000038197.76047.83

[17] Aichner, B., Bussian, B., Lehnik-Habrink, P. and Hein, S. (2013) Levels and Spatial Distribution of Persistent Organic Pollutants in the Environment: A Case Study of German Forest Soils. Environmental Science \& Technology, 47, 12703-12714. https://doi.org/10.1021/es4019833

[18] Lehnik-Habrink, P., Hein, S., Win, T., Bremser, W. and Nehls, I. (2010) Multi-Residue Analysis of PAH, PCB, and OCP Optimized for Organic Matter of Forest Soil. Journal of Soils and Sediments, 10, 1487-1498. 
https://doi.org/10.1007/s11368-010-0241-3

[19] Fraunhofer IME, Schmallenberg, Germany. http://www.refesol.de/english/index.shtml

[20] Düwel, O., Siebner, C.S., Utermann, J. and Krone, F. (2007) Gehalte an Organischer Substanz in Oberböden Deutschlands. Bundesanstalt für Geowissenschaften und Rohstoffe.

https://www.google.ie/url?sa=t\&rct=j\&q=\&esrc=s\&source=web\&cd=1\&cad=rja\&ua $\mathrm{ct}=8 \& v e d=0$ ahUKEwiasZyJiNDUAhUqKcAKHWF6A3gQFggvMAA\&url=https\%3 A\%2F\%2Fwww.bgr.bund.de\%2FDE\%2FThemen\%2FBoden\%2FProdukte\%2FSchrif ten\%2FDownloads\%2FHumusgehalte_Bericht.pdf\%3F_blob\%3DpublicationFile\& usg=AFQjCNFl395ygTKjYGMiLN2IP9T5wSeZuw

[21] Bundes-Bodenschutz- und Altlastenverordnung (1999).

[22] Vogel, S., Märker, M., Rellini, I., Hoelzmann, P., Wulf, S., Robinson, M., Steinhübel, L., Di Maio, G., Imperatore, C., Kastenmeier, P., Liebmann, L., Esposito, D. and Seiler, F. (2016) From a Stratigraphic Sequence to a Landscape Evolution Model: Late Pleistocene and Holocene Volcanism, Soil Formation and Land Use in the Shade of Mount Vesuvius (Italy). Quaternary International, 394, 155-179.

[23] DIN ISO 10382 (2002) Bodenbeschaffenheit-Bestimmung von Organochlorpestiziden und polychlorierten Biphenylen-Gaschromatographisches Verfahren mit Elektronenein fang-Detektor.

[24] Shen, L. and Wania, F. (2005) Compilation, Evaluation, and Selection of Physical-Chemical Property Data for Organochlorine Pesticides. Journal of Chemical \& Engineering Data, 50, 742-768. https://doi.org/10.1021/je049693f

[25] Wang, W., Meng, B., Lu, X., Liu, Y. and Tao, S. (2007) Extraction of Polycyclic Aromatic Hydrocarbons and Organochlorine Pesticides from Soils: A Comparison between Soxhlet Extraction, Microwave-Assisted Extraction and Accelerated Solvent Extraction Techniques. Analytica Chimica Acta, 602, 211-222.

[26] Hofman, J., Rhodes, A. and Semple, K.T. (2008) Fate and Behaviour of Phenanthrene in the Natural and Artificial Soils. Environmental Pollution, 152, 468-475.

[27] United States Environmental Protection Agency (2007) SW-846, Method 8081B: Organochlorine Pesticides by Gas Chromatography.

[28] Ferguson, J.A. and Korte, F. (1977) Epoxidation of Aldrin to Exo-Dieldrin by Soil Bacteria. Applied and Environmental Microbiology, 34, 7-13.

[29] Jorgenson, J.L. (2001) Aldrin and Dieldrin: A Review of Research on Their Production, Environmental Deposition and Fate, Bioaccumulation, Toxicology, and Epidemiology in the United States. Environmental Health Perspectives, 109, 113-139.

[30] Foreman, W.T. and Gates, P.M. (1997) Matrix-Enhanced Degradation of $p, p^{\prime}$-DDT during Gas Chromatographic Analysis: A Consideration. Environmental Science \& Technology, 31, 905-910. https://doi.org/10.1021/es960671q

[31] Erney, D.R., Gillespie, A.M., Gilvydis, D.M. and Poole, C.F. (1993) Explanation of the Matrix-Induced Chromatographic Response Enhancement of Organophosphorus Pesticides during Open Tubular Column Gas Chromatography with Splitless or Hot On-Column Injection and Flame Photometric Detection. Journal of Chromatography $A, 638,57-63$.

[32] Pignatello, J.J. (1998) Soil Organic Matter as a Nanoporous Sorbent of Organic Pollutants. Advances in Colloid and Interface Science, 76-77, 445-467.

[33] Björklund, E., Bøwadt, S., Mathiasson, L. and Hawthorne, S.B. (1999) Determining PCB Sorption/Desorption Behavior on Sediments Using Selective Supercritical Fluid Extraction. 1. Desorption from Historically Contaminated Samples. Environ- 
mental Science \& Technology, 33, 2193-2203. https://doi.org/10.1021/es981071p

[34] Xing, B. (1997) The Effect of the Quality of Soil Organic Matter on Sorption of Naphthalene. Chemosphere, 35, 633-642.

[35] Evans, J., Kaake, R.H., Orr, M. and Watwood, M. (1998) A Comparison of Ultrasonication and Soxhlet Methods for DDT Extraction from Soil. Journal of Soil Contamination, 7, 589-597.

[36] Hubert, A., Wenzel, K.-D., Manz, M., Weissflog, L., Engewald, W. and Schüürmann, G. (2000) High Extraction Efficiency for POPs in Real Contaminated Soil Samples Using Accelerated Solvent Extraction. Analytical Chemistry, 72, 1294-1300. https://doi.org/10.1021/ac9910051

[37] Salvadó, V., Alcaide, A., Carandell, N. and Hidalgo, M. (2001) Evaluation of Extraction Procedures of Organochlorine Pesticides from Natural Waters and Sediments. International Journal of Environmental Analytical Chemistry, 81, 243-256. https://doi.org/10.1080/03067310108044247

[38] Wang, P., Zhang, Q., Wang, Y., Wang, T., Li, X., Ding, L. and Jiang, G. (2010) Evaluation of Soxhlet Extraction, Accelerated Solvent Extraction and MicrowaveAssisted Extraction for the Determination of Polychlorinated Biphenyls and Polybrominated Diphenyl Ethers in Soil and Fish Samples. Analytica Chimica Acta, 663, 43-48.

[39] Zuloaga, O., Etxebarria, N., Fernández, L.A. and Madariaga, J.M. (1998) Comparison of Accelerated Solvent Extraction with Microwave-Assisted Extraction and Soxhlet for the Extraction of Chlorinated Biphenyls in Soil Samples. TrAC Trends in Analytical Chemistry, 17, 642-647.

[40] Sporring, S., Bøwadt, S., Svensmark, B. and Björklund, E. (2005) Comprehensive Comparison of Classic Soxhlet Extraction with Soxtec Extraction, Ultrasonication Extraction, Supercritical Fluid Extraction, Microwave Assisted Extraction and Accelerated Solvent Extraction for the Determination of Polychlorinated Biphenyls in Soil. Journal of Chromatography A, 1090, 1-9.

[41] DIN EN 16167 (2012) Schlamm, behandelter Bioabfall und Boden-Bestimmung von polychlorierten Biphenylen (PCB) mittels Gaschromatographie mit massenspektrometrischer Detektion (GC-MS) und Gaschromatographie mit Elektroneneinfangdetektion (GC-ECD).

[42] Wylie, P.L., Klein, K.J., Thompson, M.Q. and Hermann, B.W. (1992) Using Electronic Pressure Programming to Reduce the Decomposition of Labile Compounds during Splitless Injection. Journal of High Resolution Chromatography, 15, 763 768. https://doi.org/10.1002/jhrc.1240151112

[43] Phillips, D.D., Pollard, G.E. and Soloway, S.B. (1962) Insecticide Analysis, Thermal Isomerization of Endrin and Its Behavior in Gas Chromatography. Journal of Agricultural and Food Chemistry, 10, 217-221. https://doi.org/10.1021/jf60121a014

[44] United States Environmental Protection Agency (1999) SW-846, Method 8080A: Organochlorine Pesticides by Gas Chromatography. Organochlorine Pesticides and Polychlorinated Biphenyls by Gas Chromatography.

[45] Westland, J., Organtini, K. and Dorman, F.L. (2012) Evaluation of Lifetime and Analytical Performance of Gas Chromatographic Inlet Septa for Analysis of Reactive Semivolatile Organic Compounds. Journal of Chromatography A, 1239, 72-77.

[46] de Nijs, R.C.M., Franken, J.J., Dooper, R.P.M., Rijks, J.A., de Ruwe, H.J.J.M. and Schulting, F.L. (1978) Comparison of Methods for the Deactivation of Glass OpenTubular Columns with PEG 20M. Journal of Chromatography A, 167, 231-241.

[47] Franken, J.J., De Nijs, R.C.M. and Schulting, F.L. (1977) Deactivation of Glass 
Open-Tubular Columns with PEG 20M via the Gas Phase. Journal of Chromatography $A, 144,253-256$.

[48] Stan, H.J. and Goebel, H. (1984) Evaluation of Automated Splitless and Manual On-Column Injection Techniques Using Capillary Gas Chromatography for Pesticide Residue Analysis. Journal of Chromatography A, 314, 413-420.

[49] Rahman, M.M., Abd El-Aty, A.M. and Shim, J.-H. (2013) Matrix Enhancement Effect: A Blessing or a Curse for Gas Chromatography?-A Review. Analytica Chimica Acta, 801, 14-21.

[50] Maštovská, K., Lehotay, S.J. and Anastassiades, M. (2005) Combination of Analyte Protectants to Overcome Matrix Effects in Routine GC Analysis of Pesticide Residues in Food Matrixes. Analytical Chemistry, 77, 8129-8137. https://doi.org/10.1021/ac0515576

[51] Tsipi, D., Botitsi, H. and Economou, A. (2015) Mass Spectrometry for the Analysis of Pesticide Residues and Their Metabolites. John Wiley \& Sons, Hoboken, NJ.

Submit or recommend next manuscript to SCIRP and we will provide best service for you:

Accepting pre-submission inquiries through Email, Facebook, LinkedIn, Twitter, etc. A wide selection of journals (inclusive of 9 subjects, more than 200 journals)

Providing 24-hour high-quality service

User-friendly online submission system

Fair and swift peer-review system

Efficient typesetting and proofreading procedure

Display of the result of downloads and visits, as well as the number of cited articles

Maximum dissemination of your research work

Submit your manuscript at: http://papersubmission.scirp.org/

Or contact jep@scirp.org 